\title{
The Antimelanogenic Effect of Inularin Isolated from Flowers of Inula britannica on B16F10 Melanoma Cells and Zebrafish Embryos
}

\author{
Dae Kil Jang ${ }^{1,2}$, Seung-Hyun Jung ${ }^{3}$, Ji Hye Jeong ${ }^{3}$, Hee Min Yoo ${ }^{4}$, Ik Soo Lee ${ }^{5 *}$, and Han-Seung Shin ${ }^{1 *}$ \\ ${ }^{1}$ Department of Food Science and Biotechnology, Dongguk University, Seoul 10326, Republic of Korea \\ ${ }^{2}$ StarlingForce Co., Ltd., Seoul 08511 , Republic of Korea \\ ${ }^{3}$ Department of Applied Marine Bioresource Science, National Marine Biodiversity Institute of Korea, Seocheon \\ 33662, Republic of Korea \\ ${ }^{4}$ Center for Bioanalysis, Korea Research Institute of Standards and Science, Daejeon 34113, Republic of Korea \\ ${ }^{5} \mathrm{Herbal}$ Medicine Research Division, Korea Institute of Oriental Medicine, Daejeon 34054, Republic of Korea
}

\begin{abstract}
In the search for novel, natural melanogenesis inhibitors, a new sesquiterpene, inularin, was isolated from the flowers of Inula britannica, and the structure was determined using spectroscopic and chemical methods. The antimelanogenic effects of inularin on B16F10 melanoma cells and zebrafish embryos were evaluated. Inularin dose-dependently reduced melanocyte-stimulating hormone-induced melanin production and L-DOPA oxidation in B16F10 cells. Zebrafish embryos were used to confirm the antimelanogenic activity. Inularin significantly decreased the pigmentation of embryos compared with untreated controls.
\end{abstract}

Keywords: Inula britannica, inularin, melanogenesis, B16F10 melanoma cells, zebrafish embryos

Received: March 13, 2020 Accepted: April 1, 2020

First published online: April 2, 2020

*Corresponding author I.S.L.

Phone: +82-42-868-9462 Fax: +82-42-868-9471 E-mail: knifer48@kiom.re.kr H.-S.S.

Phone: +82-31-961-5143 E-mail: spartan@dongguk.edu

Supplementary data for this paper are available on-line only at http://jmb.or.kr.

pISSN 1017-7825 elSSN 1738-8872

Copyright(C) 2020 by The Korean Society for Microbiology and Biotechnology
Melanogenesis is a complex process by which melanin is produced by melanocytes in melanosomes [1]. Melanin is responsible for skin, hair, and eye color and plays a critical role in protecting the skin against ultraviolet radiation [2]. However, excessive melanin synthesis and accumulation are associated with hyperpigmentation disorders including freckles, melasma, and senile lentigo [3]. Regulation of melanin production is therapeutically important when treating pigmentation-related disorders. Several synthetic antimelanogenic agents are known; however, only a few are used as skin-whitening agents because of various safety issues [4]. There is an increasing need for natural melanogenesis inhibitors with fewer side effects, for cosmetic and medicinal applications [5].

Inula britannica Linnaeus (Asteraceae) is well known in China ("Xuan-Fu-Hua"), as its flowers are used in traditional Chinese medicine to treat digestive disorders, bronchitis, and inflammation [6]. In a preliminary screen using B16F10 melanoma cells, we found that a flower extract of I. britannica significantly reduced melanin production [7]. However, the active principle remained unclear. Further study of I. britannica flowers yielded a new sesquiterpene, inularin. Here, we describe its isolation and structural characterization, its antimelanogenic effect in B16F10 cells, and its effect on melanin production by embryonic zebrafish.

An ethanol extract of I. britannica flowers was subjected to silica gel column chromatography and divided into four fractions (A-D) based on thin-layer chromatography (TLC) data. Fraction C, which significantly reduced melanin production $(65 \%$ inhibition at $50 \mu \mathrm{g} / \mathrm{ml})$ by B16F10 cells, was subjected to a further series of chromatographic separation steps guided by antimelanogenic activity, leading to isolation of inularin (Fig. 1A). The material was an amorphous white powder with a molecular ion peak at $\mathrm{m} / \mathrm{z} 349.1626[\mathrm{M}+\mathrm{Na}]^{+}$on highresolution electron ionization mass spectrometry (HRESIMS), corresponding to a molecular formula of $\mathrm{C}_{17} \mathrm{H}_{26} \mathrm{O}_{6}$. The ${ }^{1} \mathrm{H}-\mathrm{NMR}$ spectrum displayed the characteristic signals of paired olefinic protons at $\delta_{\mathrm{H}} 6.28(1 \mathrm{H}, \mathrm{s})$ and $5.68(1 \mathrm{H}, \mathrm{s})$, two oxygenated methine protons at $\delta_{\mathrm{H}} 5.29(1 \mathrm{H}, \mathrm{m})$ and $3.28(1 \mathrm{H}, \mathrm{dd}, J=10.4,4.8 \mathrm{~Hz})$, two singlet methyls at $\delta_{\mathrm{H}} 1.17(3 \mathrm{H}, \mathrm{s})$ and $1.03(3 \mathrm{H}, \mathrm{s})$, and an acetoxymethyl at $\delta_{\mathrm{H}} 1.95(3 \mathrm{H}, \mathrm{s})$ (Table 1$)$. The ${ }^{13} \mathrm{C}-\mathrm{NMR}$ spectrum (Table 1), combined with the distortionless enhancement by polarization transfer (DEPT) data, yielded 17 carbon signals consisting of three methyls, five methylenes, four methines, three quaternary carbons, and two carbonyl carbons; the signals at $\delta_{\mathrm{C}} 172.2$ and 21.2 were assigned to an acetoxy group. These spectroscopic data suggest that inularin is a eudesmane-type sesquiterpene with an acetoxy moiety, as are its analogs [8]. A complete assignment of the chemical shifts of inularin and its substitution pattern was made using various 2D-NMR techniques. The ${ }^{1} \mathrm{H}-{ }^{1} \mathrm{H}$ correlation spectroscopy (COSY) correlations of inularin established two segments: $\mathrm{CH}(1)-\mathrm{CH}_{2}(2)-\mathrm{CH}_{2}(3)$ and $\mathrm{CH}(5)-\mathrm{CH}_{2}(6)-\mathrm{CH}(7)-\mathrm{CH}(8)-\mathrm{CH}_{2}(9)$ (Fig. 1B). Two oxygenated methine protons at 
A<smiles>C=C(C(=O)O)[C@H]1C[C@]2(O)[C@@](C)(O)CC[C@@H](O)[C@]2(C)C[C@@H]1OC(C)=O</smiles>

B

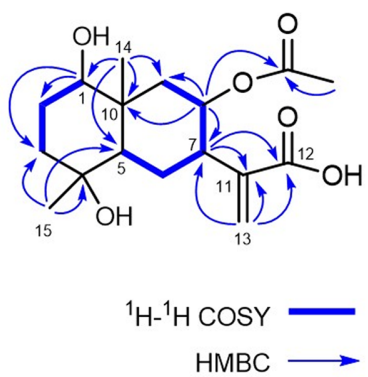

C

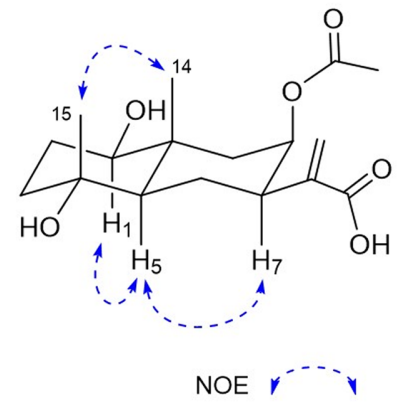

Fig. 1. Structure of inularin isolated from the flowers of I. britannica. (A) Chemical structure of inularin. (B) Key ${ }^{1} \mathrm{H}-{ }^{1} \mathrm{H}$ COSY and HMBC correlations. (C) Key NOE correlations.

$\delta_{\mathrm{H}} 5.29$ and 3.28 were assigned to $\mathrm{H}-8$ and $\mathrm{H}-1$ by the heteronuclear multiple bond correlation (HMBC) correlations of $\delta_{\mathrm{H}} 5.29$ with C-7 $\left(\delta_{\mathrm{C}} 44.2\right)$, C- $9\left(\delta_{\mathrm{C}} 45.5\right)$, and C- $10\left(\delta_{\mathrm{C}} 40.4\right)$ and those of $\delta_{\mathrm{H}} 3.28$ with C-2 $\left(\delta_{\mathrm{C}} 29.0\right)$, C-3 $\left(\delta_{\mathrm{C}} 41.9\right)$, and C-10 $\left(\delta_{\mathrm{C}} 40.4\right)($ Fig. $1 \mathrm{~B})$. The HMBC correlations of $\delta_{\mathrm{H}} 1.17\left(\mathrm{H}_{3}-15\right)$ with C-4 $\left(\delta_{\mathrm{C}} 72.3\right)$ and of $\delta_{\mathrm{H}}$ $5.29(\mathrm{H}-8)$ with the acetoxy carbon $\left(\delta_{\mathrm{C}} 172.2\right)$ indicated that the other hydroxy group was attached to $\mathrm{C}-4$, and an acetoxy moiety was linked to $\mathrm{C}-8$, respectively. The presence of an $\alpha$-methylene-carboxylic acid was inferred by carbon signals at $\delta_{\mathrm{C}} 170.0(\mathrm{COOH}, \mathrm{C}-12)$ and 143.2 and $126.1\left(\mathrm{C}=\mathrm{CH}_{2}, \mathrm{C}-11\right.$ and $\left.\mathrm{C}-13\right)$ and the $\mathrm{HMBC}$ correlation between paired olefinic protons at $\delta_{\mathrm{H}} 6.28(\mathrm{H}-13 \mathrm{a})$ and $5.68(\mathrm{H}-13 \mathrm{~b})$ and the carboxylic carbon at $\delta_{\mathrm{C}}$ 170.0 (C-12). Attachment of an $\alpha$-methylene-carboxylic acid moiety to C-7 was indicated by the HMBC crosspeaks of $\mathrm{H}-7$ with $\mathrm{C}-11$ and $\mathrm{C}-12$, and $\mathrm{H}-13$ with $\mathrm{C}-7$. The relative configuration of inularin was determined based on nuclear Overhauser effect spectroscopy (NOESY) data and comparisons of coupling constants with data from the literature. The coupling constant of $\mathrm{H}-5(J=12.0,5.6 \mathrm{~Hz})$ suggested a trans-fused eudesmane skeleton [9]. The NOE correlations (Fig. 1C) between $\mathrm{H}-1 / \mathrm{H}-5$ and $\mathrm{H}_{3}-14 / \mathrm{H}_{3}-15$ suggested that the $\mathrm{C}-1$ and $\mathrm{C}-4$ hydroxy groups were in the $\beta$ and $\alpha$ configurations, respectively. The orientation of the C-7 $\alpha$-methylene-carboxylic acid was $\beta$, as revealed by the NOE correlation between $\mathrm{H}-5 / \mathrm{H}-7$. The coupling constants of $\mathrm{H}-9 \alpha(J=14.4,3.2 \mathrm{~Hz})$ and $\mathrm{H}-9 \beta$ $(J=14.4,3.1 \mathrm{~Hz})$ indicated that $\mathrm{H}-8$ placed in ring $\mathrm{B}$ in an equatorial geometry, indicating a $\beta$-configuration of the acetoxy group at C-8. The absolute configuration of inularin was considered to be $1 R, 4 R, 5 R, 7 R, 8 R, 10 R$, as established for the co-occurring analogue eudesmolides of known absolute stereostructure [8]. Finally, the structure of inularin was established as $(1 R, 4 R, 5 R, 7 R, 8 R, 10 R)-1 \beta, 4 \alpha$-dihydroxy- $8 \beta$-acetoxy-5aH-eudesma11(13)-en-12-oic acid.

We used B16F10 cells to investigate the effect of inularin on melanogenesis. The MTT (cell viability) assay showed that inularin did not affect viability at concentrations up to $100 \mu \mathrm{M}$ (data not shown). B16F10 cells were treated with inularin at concentrations of 10,50 , and $100 \mu \mathrm{M}$. As shown in Fig. 2A, the cellular melanin content was markedly increased in the melanocyte-stimulating hormone ( $\alpha-\mathrm{MSH})$-treated control group, compared with the untreated control group, and inularin significantly reduced this increase in a dose-dependent manner. Inularin at $100 \mu \mathrm{M}$ decreased melanin production induced by $\alpha-\mathrm{MSH}$ by approximately $44 \%$, compared with the a-MSH-treated control group, whereas kojic acid exhibited only $36 \%$ inhibition even at $200 \mu \mathrm{M}$. As melanin synthesis is regulated by tyrosinase [10], we further examined the effect of inularin on cellular tyrosinase activity, as reflected by L-DOPA oxidation. As shown in Fig. 2B, inularin decreased the cellular tyrosinase activity of $\alpha$ -

Table $1 .{ }^{1} \mathrm{H}-(400 \mathrm{MHz})$ and ${ }^{13} \mathrm{C}-\mathrm{NMR}(100 \mathrm{MHz})$ data for inularin (in MeOD).

\begin{tabular}{|c|c|c|}
\hline $\mathrm{C}$ & $\delta_{\mathrm{c}}$ & $\delta_{\mathrm{H}}(\mathrm{J}$ in $\mathrm{Hz})$ \\
\hline 1 & 80.6 & $3.28 \mathrm{dd}(10.4,4.8)$ \\
\hline 2 & 29.0 & $\alpha: 1.69 \mathrm{~m}, \beta: 1.64 \mathrm{~m}$ \\
\hline 3 & 41.9 & $\alpha: 1.55 \mathrm{~m}, \beta: 1.76 \mathrm{~m}$ \\
\hline 4 & 72.3 & \\
\hline 5 & 54.6 & $1.45 \mathrm{dd}(12.0,5.6)$ \\
\hline 6 & 21.7 & $\alpha: 1.80, \beta: 1.76 \mathrm{~m}$ \\
\hline 7 & 44.2 & $2.81 \mathrm{~m}$ \\
\hline 8 & 71.5 & $5.29 \mathrm{~m}$ \\
\hline 9 & 45.5 & $\alpha: 2.17 \mathrm{dd}(14.4,3.2), \beta: 1.43 \mathrm{dd}(14.4,3.1)$ \\
\hline 10 & 40.4 & \\
\hline 11 & 143.2 & \\
\hline 12 & 170.0 & \\
\hline 13 & 126.1 & $6.28 \mathrm{~s}, 5.68 \mathrm{~s}$ \\
\hline 14 & 16.1 & $1.03 \mathrm{~s}$ \\
\hline 15 & 22.8 & $1.17 \mathrm{~s}$ \\
\hline $\mathrm{CH}_{3} \underline{\mathrm{CO}}$ & 172.2 & \\
\hline$\underline{\mathrm{CH}_{3} \mathrm{CO}}$ & 21.2 & $1.95 \mathrm{~s}$ \\
\hline
\end{tabular}



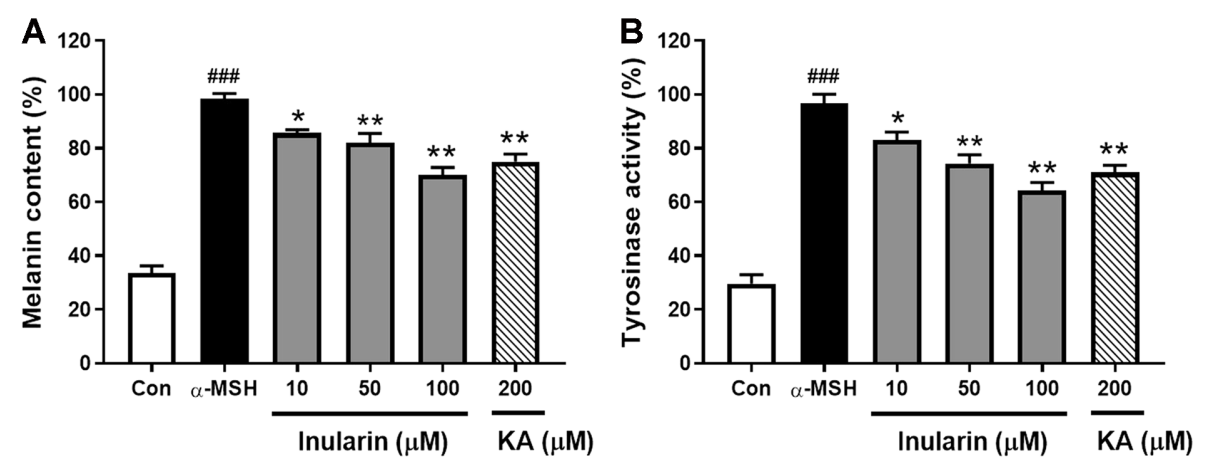

Fig. 2. Effect of inularin on the melanogenesis of $\alpha-\mathrm{MSH}$-induced B16F10 cells. B16F10 cells were stimulated with $100 \mathrm{nM} \alpha$-MSH for $36 \mathrm{~h}$ after pretreatment with the indicated concentrations of inularin $(10,50$, or $100 \mu \mathrm{M})$ or kojic acid (KA, $200 \mu \mathrm{M}$ ) for $12 \mathrm{~h}$. (A) The melanin content was measured at $405 \mathrm{~nm}$ using a microplate reader. (B) Tyrosinase levels were assayed by measuring L-DOPA oxidation at $475 \mathrm{~nm}$ using a microplate reader. The values are means \pm SD from three independent experiments. $\# \# p<0.001$ vs. Control, ${ }^{*} p<0.05$ vs. $\alpha$-MSH group, ${ }^{* *} p<0.01$ vs. $\alpha$-MSH group.

MSH-stimulated B16F10 cells in a dose-dependent manner.

The zebrafish serves as a useful model for phenotype-based screening of melanogenic inhibitors or stimulators [11]. We explored the effects of inularin on melanin pigmentation in embryonic zebrafish. Embryos were exposed to inularin at 10,50 , and $100 \mu \mathrm{M}$ commencing at $10 \mathrm{~h}$ post fertilization (hpf), and melanin levels were assayed at $48 \mathrm{hpf}$. Melanin production was strongly increased in the untreated control group; inularin reduced pigment production in a dose-dependent manner (Fig. 3A). Inularin at 10,50, and $100 \mu \mathrm{M}$ reduced pigmentation by approximately $20 \%, 25 \%$, and $44 \%$, respectively, compared with the untreated control group (Fig. 3B). Phenylthiourea (PTU) reduced pigmentation by $81 \%$ at $200 \mu \mathrm{M}$, whereas kojic acid did not show any significant effect at $200 \mu \mathrm{M}$ (data not shown), but reduced pigmentation by $13 \%$ at $1 \mathrm{mM}$ (Fig. 3B).

Sesquiterpenes are the 15-carbon subgroup of terpenoids and characteristic of Inula species. In the Inula species, most sesquiterpenes occur in a lactonized form and exert various biological properties, including anti-

A

\section{A}

¿
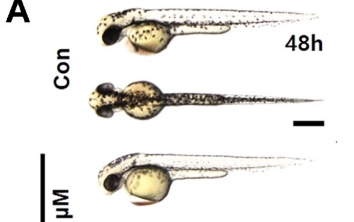

$\stackrel{\circ}{\circ}$
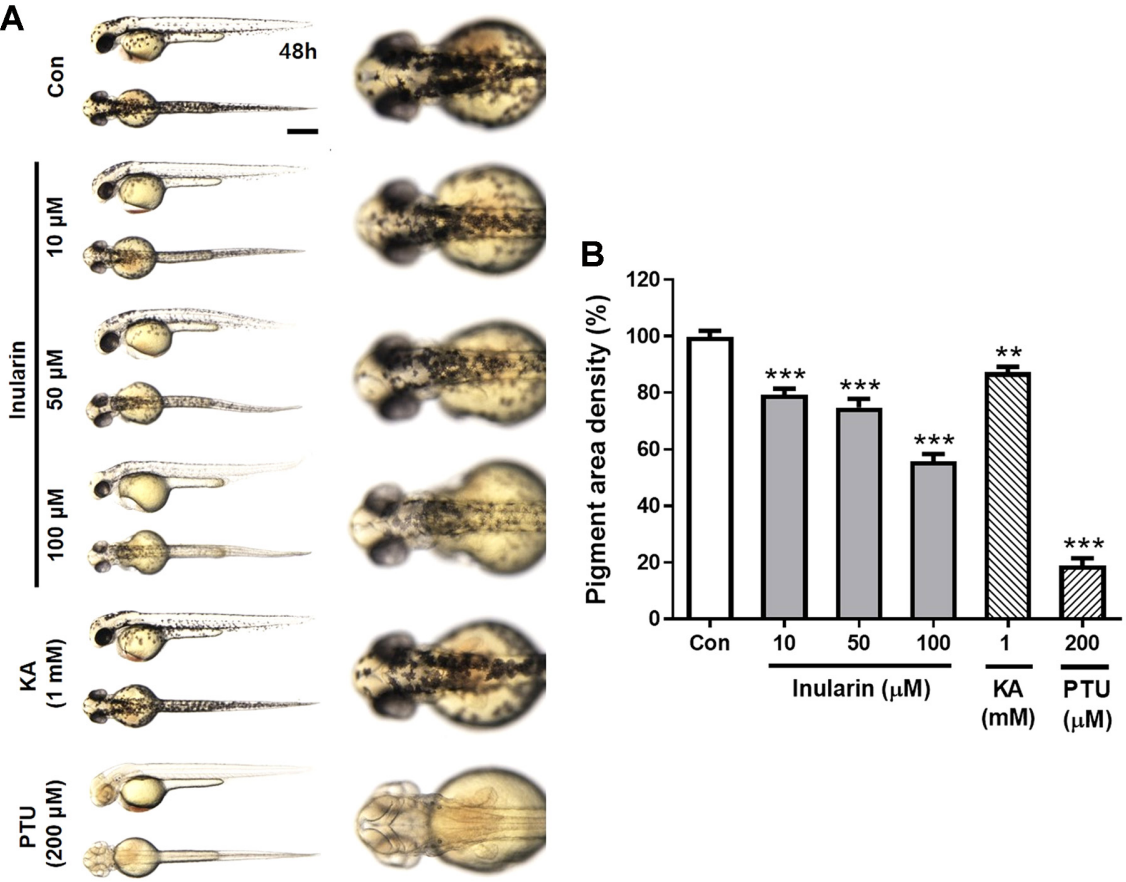

Fig. 3. Effect of inularin on melanin production in zebrafish embryos. Zebrafish embryos were treated with inularin $(10,50$, or $100 \mu \mathrm{M})$, kojic acid (KA, $1 \mathrm{mM}$ ), phenylthiourea (PTU, $200 \mu \mathrm{M})$, or 0.1\% (v/v) DMSO (Control). (A) Pigmentation in the embryos was observed under a stereomicroscope (lateral and dorsal views) at $48 \mathrm{hpf}$. Scale bar: $0.5 \mathrm{~mm}$. (B) The pigmented area density was normalized to that of control embryos using Image J software $(n=8)$. The values are means \pm SEM from three independent experiments. ${ }^{* *} p<0.01$ vs. Control, ${ }^{* * *} p<0.001$ vs. Control. 
inflammatory, antibacterial, anticancer, and cytotoxic activities $[12,13]$. It has been reported that the cytotoxicity of sesquiterpene lactones is critically dependent upon the presence of the $\alpha$-methylene- $\gamma$-lactone moiety $[14,15]$. Thus, the low cytotoxicity of inularin on B16F10 cells could be related to the absence of this moiety. So far, two sesquiterpenes, 1-O-acetylbritannilactone and britannilactone, isolated from I. britannica flowers have been reported to exhibit antimelanogenic activities in vitro [7]. These results suggest that the plant antimelanogenic activity is attributable in part to its sesquiterpenes. I. britannica flowers and inularin are promising therapeutics for melanogenesis-related diseases. The specific mechanisms involved require further study.

\section{Acknowledgments}

This work was supported by National Marine Biodiversity Institute Research Program [2020M00600] funded by the Ministry of Oceans and Fisheries (MOF), a grant (KSN2012330) from the Korea Institute of Oriental Medicine, and the Korea Institute of Planning and Evaluation for Technology in Food, Agriculture, Forestry (IPET) through the Agricultural Research Center Project, funded by the Ministry of Agriculture, Food and Rural Affairs (MAFRA; 710013-03-2-SB120).

\section{Conflict of Interest}

The authors have no financial conflicts of interest to declare.

\section{References}

1. Bonaventure J, Domingues MJ, Larue L. 2013. Cellular and molecular mechanisms controlling the migration of melanocytes and melanoma cells. Pigment Cell Melanoma Res. 26: 316-325.

2. Slominski A, Tobin DJ, Shibahara S, Wortsman J. 2004. Melanin pigmentation in mammalian skin and its hormonal regulation. Physiol. Rev. 84: 1155-1228.

3. Ebanks JP, Wickett RR, Boissy RE. 2009. Mechanisms regulating skin pigmentation: the rise and fall of complexion coloration. Int. J. Mol. Sci. 10: 4066-4087.

4. Nakagawa M, Kawai K, Kawai K. 1995. Contact allergy to kojic acid in skin care products. Contact Dermatitis. 32: 9-13.

5. Lee KT, Kim BJ, Kim JH, Heo MY, Kim HP. 1997. Biological screening of 100 plant extracts for cosmetic use (I): inhibitory activities of tyrosinase and DOPA auto-oxidation. Int. J. Cosmet. Sci. 19: 291-298.

6. Khan AL, Hussain J, Hamayun M, Gilani SA, Ahmad S, Rehman G, et al. 2010. Secondary metabolites from Inula britannica L. and their biological activities. Molecules 15: 1562-1577.

7. Choo SJ, Ryoo IJ, Kim KC, Na M, Jang JH, Ahn JS, et al. 2014. Hypo-pigmenting effect of sesquiterpenes from Inula britannica in B16 melanoma cells. Arch. Pharm. Res. 37: 567-574.

8. Qin JJ, Jin HZ, Zhu JX, Fu JJ, Zeng Q, Cheng XR, et al. 2010. New sesquiterpenes from Inula japonica Thunb. with their inhibitory activities against LPS-induced NO production in RAW264.7 macrophages. Tetrahedron 66: 9379-9388.

9. El-Ghazouly MG, El-Sebakhy NA, El-Din AAS, Zdero C, Bohlmann F. 1987. Sesquiterpene xylosides from Iphiona scabra. Phytochemistry 26: 439-443.

10. Sturm RA, Teasdale RD, Box NF. 2001. Human pigmentation genes: identification, structure and consequences of polymorphic variation. Gene 277: 49-62.

11. Choi TY, Kim JH, Ko DH, Kim CH, Hwang JS, Ahn S, et al. 2007. Zebrafish as a new model for phenotype-based screening of melanogenic regulatory compounds. Pigment Cell Res. 20: 120-127.

12. Seca AML, Grigore A, Pinto DCGA, Silva AMS. 2014. The genus Inula and their metabolites: From ethnopharmacological to medicinal uses. J. Ethnopharmacol. 154: 286-310.

13. Wang GW, Qin JJ, Cheng XR, Shen YH, Shan L, Jin HZ, et al. 2014. Inula sesquiterpenoids: structural diversity, cytotoxicity and antitumor activity. Expert Opin. Inv. Drug 23: 317-345.

14. Saúde-Guimarães DA, Raslan DS, Oliveira AB. 2014. In vitro antitumor activity of sesquiterpene lactones from Lychnophora trichocarpha. Rev. Bras. Plants Med. 16: 275-282.

15. Kupchan SM, Eakin MA, Thomas AM. 1971. Tumor inhibitors. 69. Structure-cytotoxicity relationships among the sesquiterpene lactones. J. Med. Chem. 14: 1147-1152. 